\title{
Evaluation of Seismic Analysis Procedures for Concrete Moment- Resistant Frames with Horizontal Re-entrant Corners Irregularity
}

\author{
Anis S. Shatnawi ${ }^{\# 1}$, Mazen Musmar ${ }^{\# 2}$, Laith I. Gharaibeh ${ }^{\# 3}$ \\ \# Department of Civil Engineering, The University of Jordan, Amman 11942, Jordan \\ E-mail: ' ashatnawi@ju.edu.jo; ${ }^{2}$ mazen.musmar@gmail.com; ${ }^{3}$ lyt8131775@fgs.ju.edu.jo
}

\begin{abstract}
Seismic design codes and standards such as the IBC 2012 and ASCE/SEI 7-10 allow using different seismic analysis procedures for buildings having horizontal re-entrant corner irregularity. However, such codes allow using Equivalent Lateral Force (ELF) procedure for buildings having re-entrant corner irregularity but not exceeding $50 \mathrm{~m}$ in height. This study aims to quantify the limits on building height and on the percentage of the re-entrant corner of the building, where ELF procedure may not produce reasonable results when compared to Response Spectrum (RS) and Response Time History (TH) procedures. Usually, these limits in seismic design standards are based on judgments and experience rather than quantification studies. Based on the results of this study, it is observed that using ELF method mostly overestimates maximum displacements and drift ratio. However, this method can be used safely up to 12-storey buildings, because the maximum underestimation of column shear forces for buildings with higher stories gives $30 \%$ less compared to other procedures. Moreover, it has been found that the maximum underestimation of column shear forces for buildings without re-entrant corner is $0 \%$ less than those with re-entrant corners. Furthermore, buildings analyzed by ELF method are also exposed to have a higher percentage value of underestimation of column shear forces as the case of 12-story buildings with $40 \%$ less when compared to TH Procedure. Also, the column at the re-entrant corner is not effectively affected until a re-entrant corner of $25 \%$ exists in buildings. Thus the ASCE/SEI 7-10the 's limit for using ELF procedure for buildings with re-entrant corner irregularity may be increased from $15 \%$ to $25 \%$ with less conservative results.
\end{abstract}

Keywords — seismic analysis; equivalent lateral force; response spectrum; time history; irregularity; re-entrant corner.

\section{INTRODUCTION}

Many studies were found in the literature for seismic analysis of structures with vertical and horizontal irregularity [1], [7]. Also, the seismic analyses using static or dynamic procedures are a controversial topic, because many studies showed that Equivalent Lateral Force (ELF) procedure is practical and safe for a large variety of structures [1]. The limitations on the applicability of this method on many building codes, such as the Uniform Building Code (UBC 97), are unnecessarily conservative for irregular structures [2]. Furthermore, even rigid mass irregularity structures designed with static analysis do not result in substantial negative effects on their seismic performance, and using dynamic analyses does not improve the seismic performance significantly [3]. In this study, buildings having horizontal re-entrant corner irregularity have been examined to quantify the proper limits on building height and the percentage of the re-entrant corner of the building [8], [9]. Meanwhile, ELF procedure may not produce reasonable results, when it is compared to Response Spectrum (RS) and Response Time History (TH) procedures, with using El-Centro as artificially adjusted records by response matching technique.
ASCE/SEI 7-10 defines re-entrant corner irregularity to exist where both plan projections of the structure beyond a re-entrant corner are greater than $15 \%$. Also, it allows using ELF for buildings having re-entrant corner irregularity and not exceeding $50 \mathrm{~m}$ in height. However, these limits are based on judgments rather than quantification studies. Up to our knowledge, this is the first study that examines the applicability of ELF procedure for buildings having different percentages of re-entrant corner irregularities.

\section{MATERIAL AND METHODS}

The present study deals with the evaluation of the response of particular reinforced concrete moment-resisting frame (SMRF) using ETABS v.15 software program. The effect of the re-entrant corner as plan irregularity has been evaluated for buildings having $(0 \%, 10 \%, 15 \%, 25 \%$ and $35 \%$ ) of re-entrant corners and varying the number of stories from four stories up to thirty-two stories incrementally increased by four stories at each case of study. Moreover, the effects of the seismic design categories (SDCs) B, C, D and $\mathrm{E}$ along with different seismic analysis procedures have also been investigated. The plan views of the buildings with different percentage of the re-entrant corner are shown in Fig. 
1. Besides, Fig. 2 shows the 3-D view as a sample illustration with detailed description and data of building models [10].

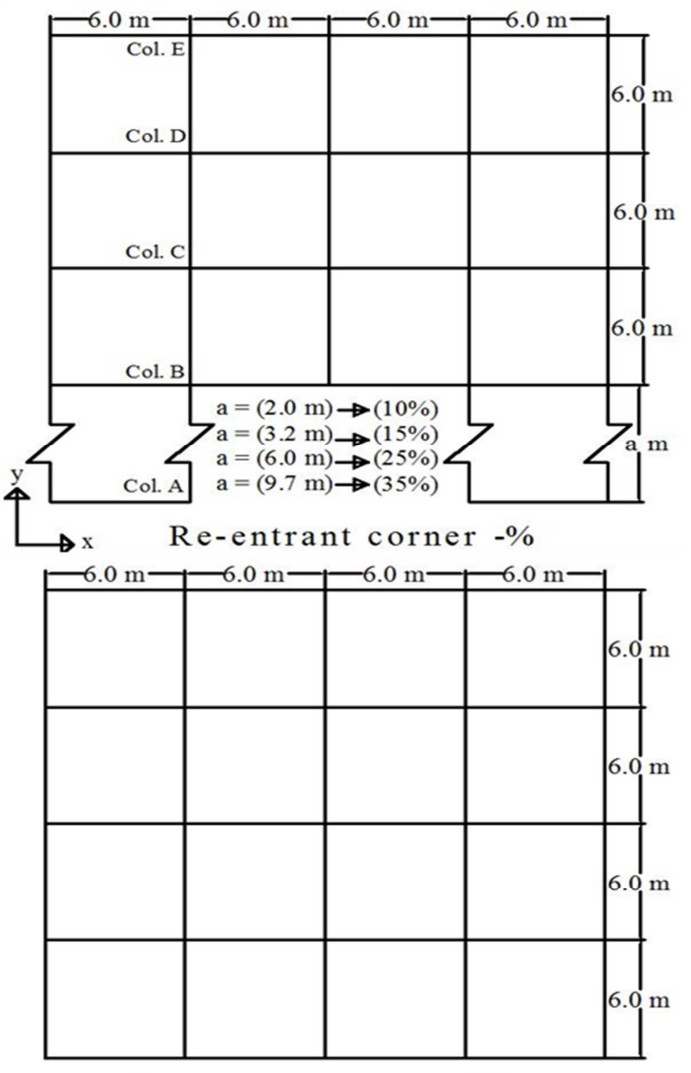

Re-entrant corner $0 \%$

Fig. 1 Plan of selected building models

The ELF's base shear equations with different SDCs are shown in Fig. 3. Eq. 12.8.5 of ASCE/SEI 7-10 needs not to be considered in displacement calculations [11], but a similar proposal was not permitted for the case of using Eq. 12.8.6. of ASCE/SEI 7-10. Though, these equations are still required for base shear calculations.
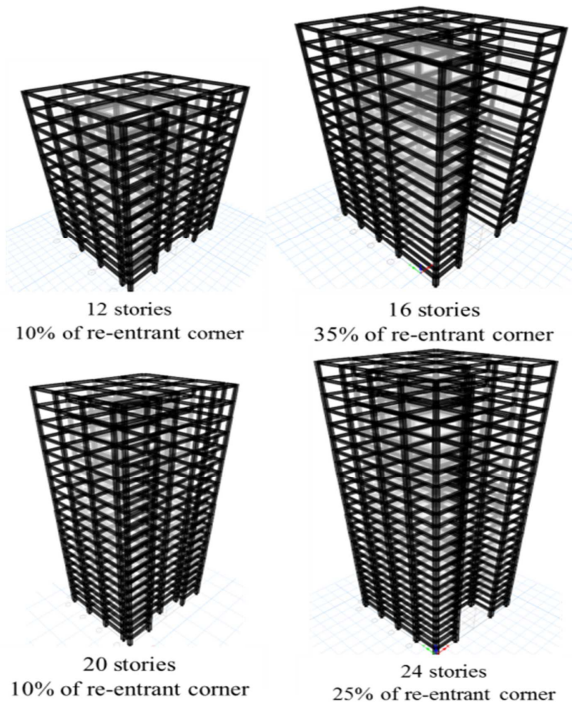

Fig. 2 Three dimensional building models

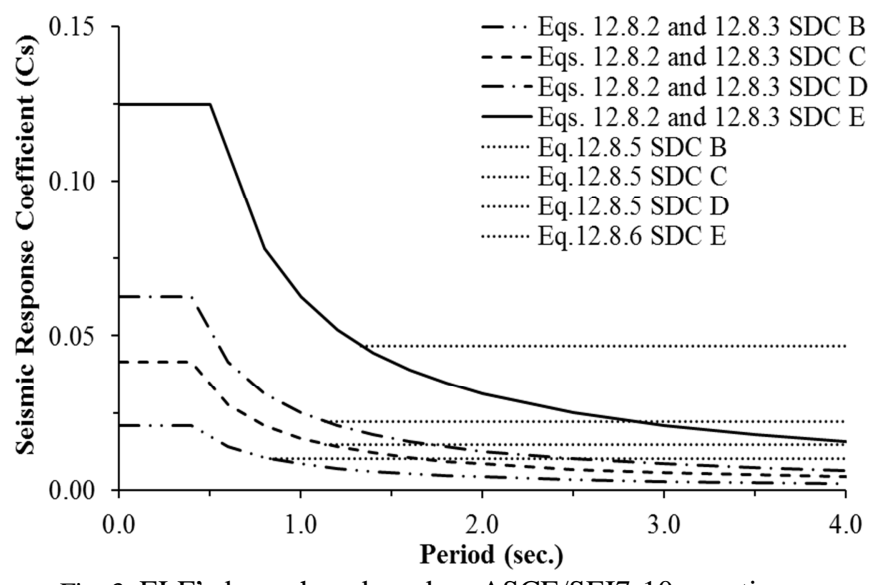

Fig. 3 ELF's base shear based on ASCE/SEI7-10 equations

The value of transition period $\left(\mathrm{T}_{\mathrm{s}}\right)$ is the same in SDCs B, $\mathrm{C}$, and $\mathrm{D}$, while it differs in SDC E. The hazard levels between SDCs B, C and D can be roughly represented as follows ( $\mathrm{SDC} \mathrm{B}=1 / 2 \mathrm{SDC} \mathrm{C}=1 / 3 \mathrm{SDC} \mathrm{D}$ ). The $\mathrm{N}-\mathrm{S}$ component of May 1940 El-Centro record was adjusted by using the spectral matching technique to allow comparing its results throughout different SDCs, which in turn is a nonuniform scaling of a ground earthquake motion to match its response spectrum with some target spectrum [12]. Fig. 4 shows the illustration of N-S component of May 1940 ElCentro record. Moreover, Fig. 5 shows response spectrums of matched earthquake records with their targeted response spectrums counterparts besides for different seismic design categories (SDCs).

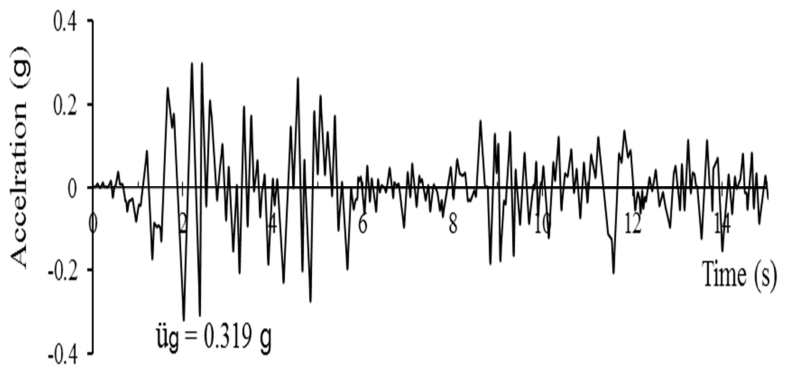

Fig. 4 The N-S component of the acceleration of May 1940 El Centro record

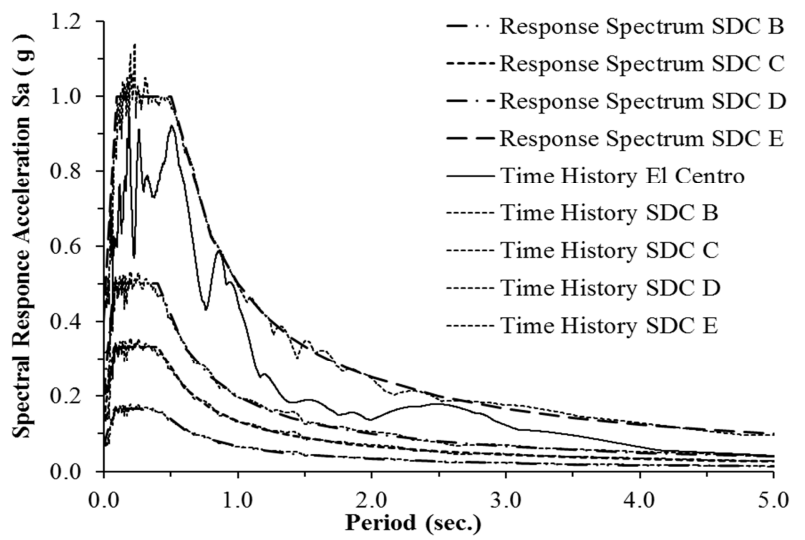

Fig. 5 Earthquake time history and their targeted response spectrums for different seismic design categories (SDCs) 


\section{RESULTS AND DISCUSSION}

The applicability of ELF as restricted by ASCE/SEI 7-10 has been examined for RC SMRF buildings with the different percent of re-entrant corners. ASCE/SEI 7-10 permits the use of all procedures of seismic design for structures not exceeding $50 \mathrm{~m}$ in height and having a horizontal irregularity of re-entrant corner. For buildings higher than $50 \mathrm{~m}$, according to ASCE/SEI 7-10, ELF is not allowed to be used in SDCs D and E. The horizontal displacement, drift ratio, and column shear force responses using ELF, RS, and TH methods are introduced as summary results, while the detailed data and results [10].

\section{A. Fundamental Period}

The natural vibrational periods for buildings with or without re-entered corners are increased as the height of the building is increased. However, natural vibrational periods of buildings with re-entrant corners increased from $10 \%$ to $35 \%$ vary in a range of $4.64 \%$ less to $7.94 \%$ higher relative to those with $0 \%$ re-entrant corner. In most cases, natural vibrational periods increased as the percentage of the reentered corner increased. Generally speaking, building tends to be more flexible as its height, and re-entrant corner percent is increased. A similar result [13]. Besides, ASCE/SEI 7-10's approximate formula for period calculations gives the same periods for buildings with the different percent of the re-entrant corner and having the same height. This is because this formula depends only on the height of the structure and does not take into account the effect of the re-entrant corners.

\section{B. Displacement and drift ratio}

Throughout comparisons on lateral displacements and drift ratios, which are shown in Fig. 6 and Fig. 7, the following observations were noticed. The maximum lateral displacement using ELF is higher by a range of $8.7 \%$ to $55.3 \%$ compared to that obtained by using RS method. Also, it is higher by a range of $20.3 \%$ to $71.6 \%$ compared to that obtained by using TH method. Also, the maximum drift ratio using ELF is higher than that obtained by using RS method by a range of $6.9 \%$ to $46.4 \%$. However, the range of maximum drift ratio obtained by ELF is varied by $1.4 \%$ less to $54 \%$ higher when compared to those obtained by $\mathrm{TH}$ method. Based on these results, it can be noted that ELF method always overestimates maximum lateral displacements for all of the model buildings under investigation whereas the drift ratio was overestimated for most cases of model buildings under investigation with one exceptional case with negligible $1.4 \%$ decrease. Therefore, and generally speaking, it can be concluded that as the height and re-entrant corner percentages of the buildings increase, their maximum lateral displacements and drift ratios are increased.
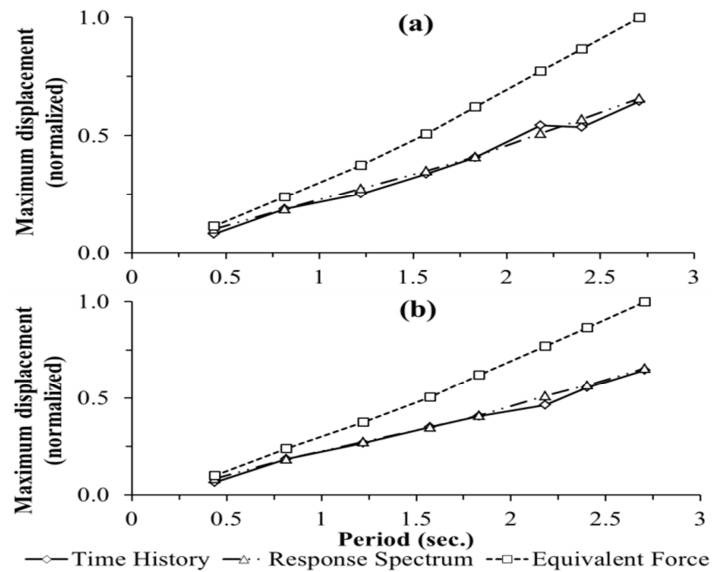

Fig. 6 Maximum displacements of buildings with $15 \%$ of the re-entrant corner: (a) SDCs B, C and D. (b) SCD E

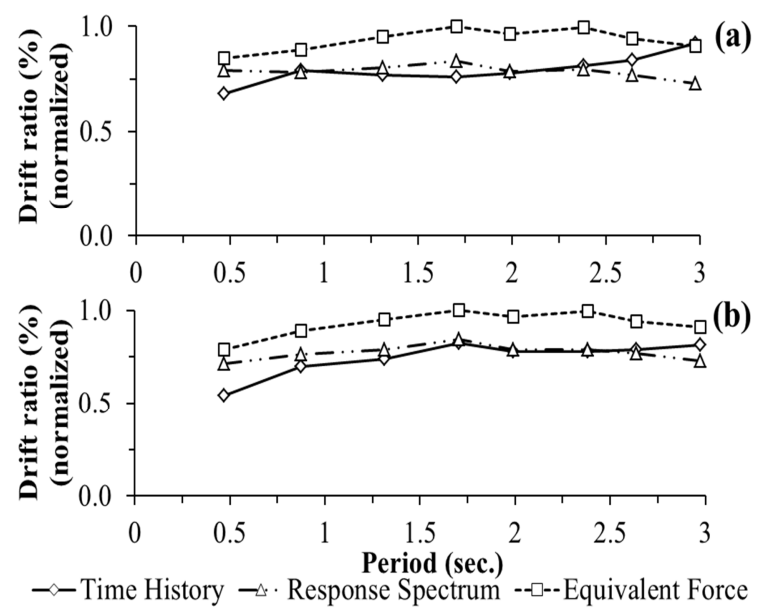

Fig. 7 Maximum drift ratio of buildings with $35 \%$ of the re-entrant corner: (a) SDCs B, C and D. (b) SCD E

\section{Columns shear forces}

1) Comparison of results of columns shear forces: The effect of the re-entrant corner and the distribution of columns shear forces along the height of structures were examined using ELF, RS and TH methods. It should be noted in Figure 1 that five columns were assigned as columns $\mathrm{A}$ to $\mathrm{E}$, which are representing the exterior and interior columns including those found at the re-entrant corner locations. ASCE/SEI 7-10 requires scaling the base shear by a factor of $85 \%$ when the base shear obtained by using RS method is less than $85 \%$ of that obtained by using ELF method. Moreover, for TH method of using Eq. 12.8.5 or Eq. 12.8.6 of ASCE/SEI 7-10, a 100\% scale factor is required. Both required scale factors were considered for RS and $\mathrm{TH}$ methods. The maximum underestimation and overestimation of column shear forces are varied along columns in the building with different height and percent of the re-entrant corner with a range of $99 \%$ less to $90 \%$ higher. 
The decrease in shear forces happens near and at the top and lower stories of the buildings because higher modes effects tend to increase shear forces at these stories [14]. Moreover, the maximum underestimations of column shear forces are found to be very high for buildings with re-entrant corners especially at Column A. This is because ELF method often underestimates responses at the flexible side of buildings [15], [16]. However, this is valid only for regular asymmetric buildings where the stiffness of the building is concentrated at one side. Also, other studies show how ELF method underestimates shear forces at higher stories and the flexible side of buildings with geometric vertical irregularity [17]. In this study, the maximum underestimation of column shear forces using ELF method when compared to $\mathrm{TH}$ method almost reaches a minimum value of $40 \%$ less at the 12 -story building in all examined percentages of re-entrant corners. It also reaches a minimum value of $33 \%$ less at the 12 -story buildings when compared to RS method. However, RS method for models with $0 \%$ of re-entrant corner gives an underestimation of column shear forces reaches almost a value of $30 \%$ less at the 20-story building. Based on these results, it can be noted that ELF method can be used safely with proper conservative column shear forces for buildings up to 12 -story in height. Table 1 and Table 2 show the ranges of percentages of change in columns' shear forces obtained by using ELF method relative to those obtained by using RS method with considering the $100 \%$ base shear scaling factor.

2) Effect of the re-entrant corner on shear forces: The lateral and vertical distribution of columns shear forces were examined to specify at which percent of the re-entrant corner, column B found at the re-entrant corner location will have higher shear forces than the other columns. Herein, it should be noted that the columns $\mathrm{B}, \mathrm{C}$, and $\mathrm{D}$ will always have larger shear forces than the exterior columns $\mathrm{A}$ and $\mathrm{E}$ because they frequently have larger cross-sections. The range of percent of shear force on column $\mathrm{B}$ relative to column $\mathrm{C}$ obtained by using ELF, RS and $\mathrm{TH}$ methods is found to be $0 \%$ for buildings with $0 \%$ of re-entrant corner, while as it generally increases as the number of stories is increased for the cases with re-entrant corner ranges from $10 \%$ to $35 \%$. It can be noted that the columns' shear forces obtained by ELF method

TABLE I

THE RANGE OF PERCENT OF COLUMNS SHEAR FORCES USING ELF RELATIVE TO RS FOR BUILDINGS WITH 10\% AND 15\% OF RE-ENTRANT CORNER

\begin{tabular}{|c|c|c|c|}
\hline \multirow{2}{*}{$\begin{array}{c}\text { Number } \\
\text { of stories }\end{array}$} & \multicolumn{3}{|c|}{$\begin{array}{c}\text { The range of percent of change in columns } \\
\text { shear forces }\end{array}$} \\
\cline { 2 - 4 } & \multirow{2}{*}{ SDC } & \multicolumn{2}{|c|}{ Percent of the re-entered corner } \\
\cline { 2 - 4 } & & $\mathbf{1 0 \%}$ & $\mathbf{1 5 \%}$ \\
\hline \multirow{2}{*}{4} & B,C,D & -16.26 to 9.22 & -15.39 to 8.70 \\
\cline { 2 - 4 } & E & -15.93 to 9.57 & -15.02 to 9.09 \\
\hline \multirow{2}{*}{8} & B,C,D & -23.77 to 12.99 & -22.41 to 11.86 \\
\cline { 2 - 4 } & E & -18.56 to 10.20 & -16.88 to 9.14 \\
\hline \multirow{2}{*}{12} & B,C,D & -32.55 to 22.36 & -37.29 to 20.24 \\
\cline { 2 - 4 } & E & -24.41 to 19.08 & -29.57 to 17.10 \\
\hline \multirow{2}{*}{16} & B,C,D & -46.67 to 24.49 & -56.79 to 21.82 \\
\hline
\end{tabular}

\begin{tabular}{|c|c|c|c|}
\hline & E & -41.08 to 25.20 & -51.99 to 22.30 \\
\hline \multirow{2}{*}{20} & B,C,D & -63.88 to 25.66 & -77.47 to 23.72 \\
\cline { 2 - 4 } & E & -59.03 to 25.84 & -74.21 to 23.86 \\
\hline \multirow{2}{*}{24} & B,C,D & -79.27 to 27.27 & -97.53 to 26.52 \\
\cline { 2 - 4 } & E & -76.52 to 26.55 & -97.20 to 26.16 \\
\hline \multirow{2}{*}{28} & B,C,D & -74.94 to 30.25 & -93.95 to 28.92 \\
\cline { 2 - 4 } & E & -72.18 to 29.47 & -93.25 to 28.27 \\
\hline \multirow{2}{*}{32} & B,C,D & -90.42 to 30.45 & -88.99 to 32.92 \\
\cline { 2 - 4 } & E & -89.28 to 29.48 & -87.65 to 32.05 \\
\hline
\end{tabular}

TABLE II

THE RANGE OF PERCENT OF COLUMNS SHEAR FORCES USING ELF RELATIVE TO RS FOR BUILDINGS WITH 25\% AND 35\% OF RE-ENTRANT CORNER

\begin{tabular}{|c|c|c|c|}
\hline \multirow{2}{*}{$\begin{array}{c}\text { Number } \\
\text { of stories }\end{array}$} & \multicolumn{3}{|c|}{ The range of percent of columns shears forces } \\
\cline { 2 - 4 } & \multirow{2}{*}{ SDC } & \multicolumn{2}{|c|}{ Percent of the re-entered corner } \\
\cline { 2 - 4 } & & $\mathbf{2 5 \%}$ & $\mathbf{3 5 \%}$ \\
\hline \multirow{2}{*}{4} & B,C,D & -11.43 to 3.63 & -22.07 to 6.06 \\
\cline { 2 - 4 } & E & -10.90 to 3.86 & -21.57 to 7.50 \\
\hline \multirow{2}{*}{8} & B,C,D & -26.17 to 6.74 & -38.35 to 13.52 \\
\cline { 2 - 4 } & E & -18.76 to 4.05 & -32.09 to 10.32 \\
\hline \multirow{2}{*}{12} & B,C,D & -44.88 to 19.01 & -54.02 to 23.30 \\
\cline { 2 - 4 } & E & -38.34 to 16.03 & -49.27 to 20.60 \\
\hline \multirow{2}{*}{20} & B,C,D & -70.62 to 24.82 & -76.98 to 28.44 \\
\cline { 2 - 4 } & E & -67.15 to 25.74 & -74.16 to 29.32 \\
\hline \multirow{2}{*}{24} & B,C,D & -95.20 to 30.74 & -99.15 to 34.25 \\
\cline { 2 - 4 } & E & -94.22 to 35.77 & -99.02 to 34.17 \\
\hline & B,C,D & -71.68 to 35.39 & -70.30 to 37.80 \\
\hline \multirow{2}{*}{28} & E & -70.18 to 34.80 & -67.26 to 37.11 \\
\hline & B,C,D & -76.81 to 38.99 & -70.20 to 40.01 \\
\hline \multirow{2}{*}{32} & E & -74.15 to 38.69 & -67.00 to 39.12 \\
\hline & B,C,D & -60.67 to 41.05 & -64.55 to 66.62 \\
\hline & E & -56.35 to 40.12 & -68.20 to 40.98 \\
\hline
\end{tabular}

Are the same for all SDCs due to its static nature. However, the columns' shear forces obtained by using RS method in SDCs B, C, and D are different from those obtained for SDC $\mathrm{E}$ due to the difference in $\mathrm{T}_{\mathrm{s}}$ as discussed earlier. On the other hand, the columns' shear forces obtained by $\mathrm{TH}$ method are changed in high scattering manner compared to those obtained by ELF and RS methods. This is because the columns' shear forces obtained by TH are depending strongly on the characteristics of the individual earthquake records used for analysis [18].

It has been seen that ELF method produces higher shear forces on column B found at the location of the re-entrant corner for all buildings with $25 \%$ of the re-entrant corner but with height up to 12-story compared to those obtained by using either RS or TH methods. Whereas, this is not the case when using TH method for buildings with $25 \%$ of re-entrant with height up to 20 -story where column B has shear forces changes in range $7.4 \%$ less to $3 \%$ higher compared relatively to columns C and D. Similarly, RS method produces shear forces at column $\mathrm{B}$ which changes in range of $2.7 \%$ less to $2 \%$ 
higher for buildings with $25 \%$ of re-entrant corner with height up to 24-story, where the same percentage of reentered corner, the ELF method produces shear forces at same columns ranges from $2.8 \%$ less to $2.6 \%$ higher but up to 28 -story in height. In all model cases with $35 \%$ of the reentrant corner, the shear forces on column B obtained by using RS and $\mathrm{TH}$ methods were found higher than other columns. However, the ELF method produces higher shear forces on column B in building with more than 20-storey in height. The results are summarized in Table 3 which shows the cases for different methods of analysis where the shear forces in column B found at the re-entrant corner location is the higher than these exerted in other columns for a different number of stories and different percentage of the re-entered corner. Results in Table 3 consider the $100 \%$ scaling factor required by ASCE/SEI 7-10.

TABLE III

CASES WHERE THE SHEAR FORCES IN COLUMN B ARE HIGHER THESE OF OTHER COLUMNS

\begin{tabular}{|c|c|c|c|c|}
\hline \multicolumn{5}{|c|}{ Cases where shear force at column B is the highest } \\
\hline $\begin{array}{c}\text { Re- } \\
\text { entrant } \\
\text { corner \% }\end{array}$ & 4 & 8 & 12 & 16 \\
\hline $0 \%$ & - & - & - & - \\
\hline $10 \%$ & - & - & - & - \\
\hline $15 \%$ & - & - & - & - \\
\hline $25 \%$ & - & - & - & - \\
\hline $35 \%$ & RS, TH & RS, TH & RS, TH & RS, TH \\
\hline \multicolumn{2}{|c|}{ Cases where shear force at column B is the highest } \\
\hline $\begin{array}{c}\text { Re- } \\
\text { entrant } \\
\text { corner \% }\end{array}$ & 20 & 24 & 28 & 32 \\
\hline $0 \%$ & - & - & - & - \\
\hline $10 \%$ & - & - & - & - \\
\hline $15 \%$ & - & - & - & - \\
\hline $25 \%$ & TH & RS, TH & All & All \\
\hline $35 \%$ & All & All & All & All \\
\hline
\end{tabular}

The ranges of a percent of increase of shear force in column B located at the re-entrant corner are generally higher using RS and TH methods than using ELF method especially for buildings with $35 \%$ of the re-entrant corner. Moreover, the maximum increase in shear forces in column B occurred for the 32-story building in SDCs B, C, and D with $35 \%$ of the re-entrant corner with an increase of $6.5 \%$, $16 \%$ and $24 \%$ when ELF, RS and $\mathrm{TH}$, respectively. However, using $\mathrm{TH}$ method for SDC E, the maximum increase in shear forces at column B occurred for the 28story building with an increase of $19.7 \%$. Based on the above results, it can be noted that the column at the reentrant corner is not effectively affected until a building have $25 \%$ of the re-entrant corner. Thus, the limit for reentrant corner irregularity given by ASCE/SEI 7-10 may be increased from $15 \%$ to $25 \%$ with acceptable conservatively level of analysis. One may keep in mind the slight increase of shear forces at the column B which is observed at the 32story building with $15 \%$ of re-entrant corner, which found to be less than $1.5 \%$ and may be considered minor with proper design.

\section{CONCLUSIONS}

The following conclusions were made based on the results of the study: Keeping in mind that ASCE/SEI 7-10's formula gives the same periods values for buildings with different percent of re-entrant corner since it depends only on the height of structure and does not take into account the effect of the re-entrant corners, it is found that the percent of natural periods of buildings with re-entrant corner relative to these with $0 \%$ of re-entrant corner increase as the height of the building is increased but increase in most cases when reentrant corner is increased.

ELF method overestimates maximum lateral displacement and drifts ratio for buildings in most cases. Moreover, and generally speaking, as the height and re-entrant corner percent of the buildings are increased, their maximum lateral displacements and drift ratio are also increased.

The applicability of ELF as restricted by ASCE/SEI 7-10 has been examined for RC SMRF buildings with the different percent of re-entrant corners. From the results of this study, it can be concluded that ELF method can be used safely for buildings up to the 12-story in height with any percent of re-entered corner horizontal irregularity because the maximum underestimation of column shear forces for buildings with more than 12-story in height gives a minimum of $30 \%$ less when compared to RS and TH methods. For buildings higher than $50 \mathrm{~m}$, according to ASCE/SEI 7-10, ELF is not allowed to be used in the presence of re-entrant corner irregularity of $15 \%$. However, from results of this study, it can be concluded that the columns at the re-entrant corner locations are not largely affected for a building having a re-entrant corner of $25 \%$. Thus, the ASCE/SEI 7-10's limitation for re-entrant corner irregularity to be considered may be acceptably increased from $15 \%$ to $25 \%$.

It should be noted that other types of horizontal irregularity such as diaphragm discontinuity and nonparallel lateral force resisting systems irregularities might be investigated.

\section{NOMENCLATURE}

ELF Equivalent Lateral Force

RS Response Spectrum

SDC Seismic Design category

TH Time History

$\mathrm{T}_{\mathrm{s}} \quad$ Transition period of vibration

\section{ACKNOWLEDGMENT}

The authors would like to thank the University of Jordan for the support and fund provided to produce this work and to contribute to the International Conference on Construction and Building Engineering (ICONBUILD 2017).

\section{REFERENCES}

[1] G. Özmen, S. Pala, E. Orakdogen, and G. Gulay, "Investigation on Vertical Structural Irregularities in Multi-story Structures," Eleventh World Conference on Earthquake Engineering, edited by Sociedad Mexicana de Ingeniería Sísmica (Elsevier Science, Oxford, 1996), Paper No. 1513. 
[2] S. Das, "Seismic Design of Vertically Irregular Reinforced Concrete Structures," Ph.D. thesis, North Carolina State University, 2000.

[3] R. Tremblay and L. Poncet, "Seismic Performance of Concentrically Braced Steel Frames in Multistory Buildings with Mass Irregularity,' J Struct Eng ASCE, vol. 131(9), pp. 1363-1375, 2005.

[4] G. Özmen, K. Girgin, and Y. Durgun, "Torsional irregularity in multi-story structures," Int J Adv Struct Eng, vol. 6, pp. 121-131, 2014.

[5] M. Fakhouri, "The Influence of Plan Geometry and Structural System on The Behavior of High-Rise Buildings," Master Thesis, The University of Jordan, Jordan, 2008.

[6] L. Peña and G. De Carvalho, "Influence of the concrete structural configuration in the seismic response," IBRACON Structures and Materials Journal, vol. 8(6), pp. 800-826, 2015.

[7] M. M. Ahmed, S. E. Abdel Raheem, M. Ahmed, and A. Abdel-Shafy, "Irregularity Effects on The Seismic Performance of L-Shaped Multi-Story Buildings," Journal of Engineering Sciences, vol. 44(5), pp. 513-536, 2016.

[8] International Code Council (ICC), International Building Code (IBC), ICC, Falls Church, VA, 2012.

[9] American Society of Civil Engineering (ASCE), Minimum Design Loads for Buildings and Other Structures, ASCE, Reston, Virginia, 2010

[10] L. Gharaibeh, "Evaluation of Different Seismic Analysis Procedures for Concrete Moment Resistant Frames with Horizontal Re-entrant Corners Irregularity," Master Thesis, The University of Jordan, 2017.
[11] F. Charney, Seismic Loads Guide To The Seismic Load Provisions of ASCE 7-05, ASCE Press, Reston, Virginia, 2010.

[12] J. Hancock, J. Watson-Lamprey, N. A. Abrahamson, J. Bommer, A. Markatis, E. McCoy, and R., Mendis, "An improved method of matching response spectra of recorded earthquake ground motion using wavelets," Journal of Earthquake Engineering, vol. 10, pp. 6789, 2006.

[13] B. Brown, "Lateral Loads on Reentrant Corner Structures," Master Thesis, Washington State University, 2014.

[14] A. K. Chopra, Dynamics of Structures: Theory and Applications to Earthquake Engineering, 4th ed., Upper Saddle River, New Jersey: Prentice-Hall, 2012.

[15] S. Dutta and R. Roy, "Seismic Demand of Low-Rise Multistory Systems with General Asymmetry," Journal of Engineering Mechanics, vol. 138(1), pp. 1-11, 2012

[16] A. Rutenberg and O. A. Pekau, "Seismic Code Provisions for Asymmetric Structures: a Re-evaluation," Eng. Struct., vol. 9, pp. 255-264, 1987.

[17] Mahato, S. and Roy, R., "Equivalent Lateral Force Method for Buildings with Setback: Adequacy in Elastic Range," Earthquakes and Structures, vol. 4 (6), pp. 685-710, 2013.

[18] NRCC. 2010b. Part 4: Commentary on the National Building Code of Canada, National Research Council of Canada, Ottawa, ON, 2010. 